\title{
IMPLEMENTASI KONSEP MEDIA SOSIAL DALAM SISTEM INFORMASI KEGIATAN KESISWAAN (STUDI KASUS : SMK XYZ)
}

\author{
Tiya Monica ${ }^{1)}$, Rohmat Indra Borman ${ }^{2)}$, Barka Satya ${ }^{3)}$ \\ 1) Sistem Informasi, Universitas Teknokrat Indonesia \\ 2) Sistem Informasi Akuntansi, Universitas Teknokrat Indonesia \\ 3) Teknik Informatika, Universitas AMIKOM Yogyakarta \\ Jl. H. Z A Pagaralam, No 9-11, Labuhanratu,Bandarlampung \\ Email : tiyamonica@yahoo.com ${ }^{1)}$, rohmat_indra@teknokrat.ac.id ${ }^{2)}$ barka.satya@amikom.ac.id $^{3)}$
}

\begin{abstract}
Abstrak
Media sosial menwarkan kemudahan dalam interaksi dan komunikasi dengan tidak tatap muka secara langsung. Kehadiran situs jejaring sosial telah menjadi sebuah media alternatif dalam mengembangkan hubungan dan komunikasi. Pada penelitian ini dilakukan penerapan konsep media sosial pada sekolah dalam pemanfaatan sharing informasi di bidang kesiswaan pada SMK XYZ. Pada sistem yang berjalan saat ini terjadi beberapa kendala diantaranya informasi yang tidak tersebar dengan baik dan tidak semua mengetahui informasinya. Untuk mengatasi hal tersebut dibutuhkan sebuah sistem informasi dengan menggunakan konsep media sosial, dimana sistem informasi akan dilakukan dengan mudah oleh para anggota organisasidan semua anggota dapat ikut berpartisipasi berbagi informasi mengenai kegiatan organisasi tersebut secara real time. Sistem informasi kegiatan kesiswaan untuk organisasi siswa pada SMK XYZ telah enerapkan konsep media sosial dengan menerapkan fitur-fitur yang harus media sosial yang terdiri dari fitus sociality, openess, contributors, contents, technology dan location.Pada pengujian respontime dengan menggunakan Apache Jmeter, sistem mampu menangani dengan baik untuk akses 50 user secara bersamaan.
\end{abstract}

Kata kunci: sistem, informasi, media sosial, kegiatan kesiswaan.

\section{Pendahuluan}

Awal mulanya komunikasi dengan menggunakan media berjalan hanya searah, dalam arti penikmat media hanya bisa menikmati konten yang disajikan sumber media. Seiring perkembangan jaman, kini orang awamsebagai penikmat media tidak lagi hanya bisa menikmati konten dari media yang terpapar padanya, namun dapat mengisi konten di media tersebut, dan kemudian disebuat sebagai sosial media. Sosial media memungkinkan komunikasi dapat dilakukan tak terbatas jarak, waktu, ruang dan dapat dilakukan dimana saja, kapan saja. Sosial media menwarkan digitalisasi interaksi dengan tidak bertatap muka terkait pembuatan pesan dan penyampaian pesan (Watie, 2011).

Kehadiran situs jejaring sosial telah menjadi sebuah media alternatif bagi individu dalam mengembangkan hubungan dengan siapa saja yang menaruh minat (Abadi, Fandrian, \& Utara, 2013). Konsep media sosial dapat diterapkan pada sekolah dalam pemanfaatan sharing informasi. Bidang kesiswaan pada SMK XYZ memiliki tugas penting diantaranya mengatur segala informasi mengenai kegiatan yang akan dilaksanakan oleh organisasi kesiswaan. Informasi mengenai waktu pelaksanaan, panitia pelaksana kegiatan, sampai pada tempat pelaksanaan kegiatan yang harus disampaikan kepada anggota organisasi kesiswaan yang terkait dalam pelaksanaan kegiatan tersebut. Pada sistem yang berjalan saat ini terjadi beberapa kendala diantaranya informasi yang tidak tersebar dengan baik dan tidak semua mengetahui informasinya, dikarenakan mereka tidak mengetahui kepada siapa mereka harus meminta informasi, sehingga dalam pelaksanaan kegiatan sering terjadi keterlambatan penyampaian informasi Untuk menangani masalah tersebut dibutuhkan sebuah sistem informasi dengan menggunakan konsep media sosial, dimana sistem informasi tersebut para anggota organisasi dapat ikut berpartisipasi dan berbagi informasi mengenai kegiatan organisasi tersebut, dimana setiap anggota dapat meberikan informasi dan dapat menanggapi informasi tersebut secara real time. Konsep sosial media digunakan agar pengguna dapat menerima informasi kapan saja dan dimana saja.

\section{Pembahasan}

\subsection{Mengidentifikasi Kebutuhan User}

Untuk identifikasi kebutuhan user dilakukan analisa terhadap kebutuhan. Analisis kebutuhan perangkat lunak merupakan proses mendapatkan informasi, model, spesifikasi sistem yang diinginkan pengguna (Simarmata, 2010). Analisis kebutuhan sistem dapat diklasifikasikan sebagai persyaratan fungsional dan nonfungsional atau sebagai persyaratan domain yang mewakili dari sistem ini sendiri (Sommerville, 2011).

\section{a) Analisis Kebutuhan Fungsional}

Kebutuhan fungsional diperlukan untuk mengetahui proses apa saja yang dapat dilakukan oleh sistem, serta siapa saja yang dapat menggunakan sistem yang dibangun. Berikut ini adalah analisis kebutuhan 
fungsional sistem informasi kegiatan kesiswaan dengan menerapkan konsep sosial media :

1. Sistem dapat digunakan sebagai media penyampaian informasi tentang kegiatan sekolah. Pada sistem ini memiliki tiga tingkat pengguna, yaitu kesiswaan, pengurus organisasi dan anggota organisasi.

2. Pada bagian kesiswaan, dapat melakukan pengelolaan data siswa yang tergabung dalam organisasi. Bagian kesiswaan dapat mengelola data organisasi, menambah pengurus organisasi, memantau aktivitas organisasi seperti melihat daftar kiriman, dan daftar komentar.

3. Pengurus organisasi dapat menambah anggota organisasi sesuai dengan organisasi yang diikuti, menulis kiriman, dan menulis komentar pada kiriman.

4. Anggota organisasi yaitu dapat melihat kiriman sesuai organisasi yang diikuti, mengirim pesan dan menulis komentar.

\section{b) Analisis Kebutuhan Non-Fungsional}

Analisa kebutuhan non-fungsional dimana dilakukan analisa terhadap batasan layanan atau fungsi yang diberikan sistem (Kosasi dan Kuway, 2012). Kebutuhan non-fungsional pada penelitian ini berupa kebutuhan hardware dan software. Berikut ini adalah sistem informasi kegiatan kesiswaan dengan menerapkan konsep sosial media :

\section{Analisis Perangkat keras}

Kebutuhan perangkat keras yang diperlukan untuk mengimplementasikan adalah sebagai berikut:

1. Processor : Intel Core i3

2. Harddisk : $500 \mathrm{~Gb}$

3. Memory : $2024 \mathrm{Mb}$

4. Monitor

5. Mouse dan Keyboard

6. Modem internet

\section{Analisis Perangkat Lunak}

Spesifikasi perangkat lunak yang dibutuhkan untuk mendukung aplikasi yang akan dibangun adalah sebagai berikut:

1. Sistem Operasi Windows 7

2. Web Server XAMPP

3. Editor Website dengan Sublime text

4. Database menggunakan $M y S Q L$.

\subsection{Analisis Konsep Media Sosial}

Fitur-fitur yang harus terdapat pada sebuah aplikasi media sosial terdiri dari fitus sociality, openess, contributors, contents, technology dan location (Schlagwein, Schoder, \& Fischbach, 2011). Berikut ini adalah analisis yang dilakukan terhada fitur-fitur implementasi konsep sosial media yang akan dikembangkan :

a) Sociality
Media sosial dapat disebut sebuah komunitas dan media ini fokus pada adanya pertukaran informasi. Jadi, sebuah aplikasi media sosial harus mempunyai fitur untuk para penggunanya agar dapat saling bertukar informasi. Pada sistem informasi kegiatan kesiswaan terdapat fitur-fitur pesan antar angoota dan dapat menanggapi kiriman dari anggota.

b) Opennes

Media sosial biasanya tidak mempunyai jumlah pengguna yang ditentukan sebelumnya. Maka pada sistem yang akan dikembangkan Semua siswa dapat berpatisipasi dan berkontribusi secara bebas sesuai keinginan mereka.

\section{c) Contributors}

Kontributor di media sosial adalah seorang individu yang bebas dan tidak terikat dengan salah satu pihak atau lebih. Pada sistem yang dikembangkan semua anggota mempunya kontribusi dengan meberikan informasi-informasi tentang kegiatan kesiswaan pada sistem.

\section{d) Contents}

Isi dari informasi yang dihasilkan dari sebuah media sosial adalah user-generated. Jadi, informasi pada sebuah aplikasi media sosial berasal dari pengguna dan informasi tersebut digunakan untuk pengguna pula.

e) Technology

Sebuah aplikasi media sosial biasanya mudah digunakan dan merupakan open source software. Pada sistem yang dikembangkan dibuat dengan tampilan yang mudah digunakan dengan menu yang tidak rumit.

\section{f) Location}

Sistem aplikasi media sosial adalah online. Jadi, pengguna aplikasi media sosial dapat berasal dari banyak lokasi asalkan terdapat koneksi internet.

\subsection{Perancangan Sistem}

Ranacangan sistem dibuat untuk mempermudah dalam implementasi sistem. Untuk mengetahui arsitektur sistem yang dikembangkan maka dirancang desain arsitektur. Arsitektur sistem pada sistem informasi kegiatan kesiswaan dimulai dari pengguna yang mengakses sistem melalui web browser (dibutuhkan koneksi jaringan), kemudian web browser melakukan request kepada web server sesuai dengan yang diinginkan pengguna. Pada web server meminta data kepada server aplikasi untuk ditampilkan kepada pengguna. Data diambil dari server database. Setelah data didapat, baru kemudian pengguna dapat melihatnya melalui web browser. Desain asiktektur sistem informasi kegiatan kesiswaan dapat dilihat pada gambar 1 berikut ini : 


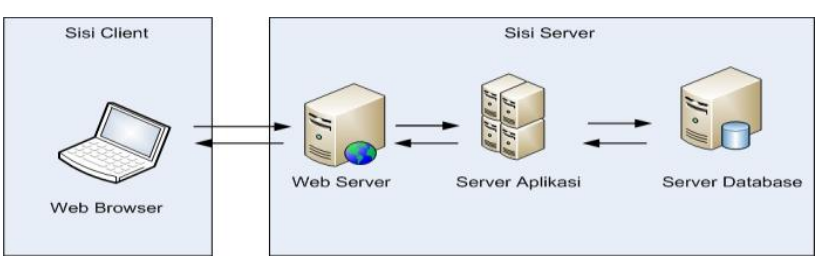

Gambar 1. Desain Asitektur Sistem Informasi Kegiatan Kesiswaan

Untuk mendapatkan gambaran mengenai sistem yang digunakan proses dan data model dari sistem dimodelkan dengan diagram use case. Use case diagram atau diagram use case merupakan pemodelan untuk prilaku(behaviour) sistem informasi yang akan dibuat. Use case mendeskripsikan sebuah interaksi antara satu atau lebih aktor dengan sistem informasi yang akan dibuat (A. S. \& Salahudin, 2013). Use case diagram dapat dilihat pada gambar 2 .

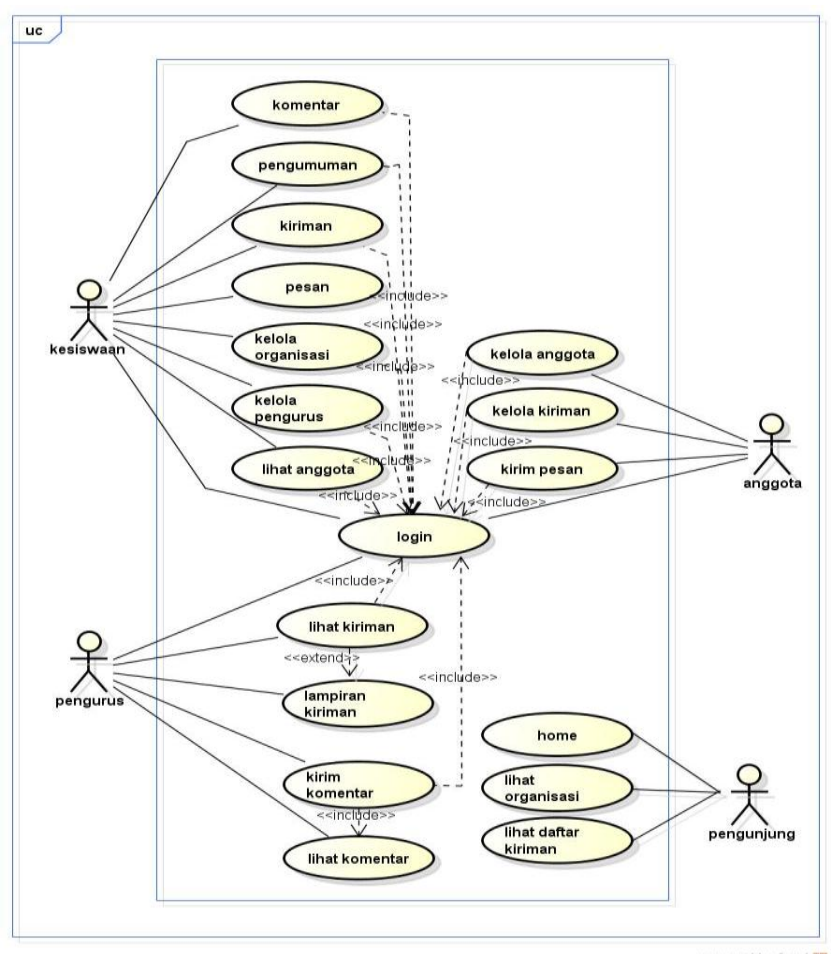

Gambar 2. Use Case Diagram Sistem Informasi Kegiatan Kesiswaan

\subsection{Implementasi dan Pengkodean}

Implementasi merupakan tahap dimana desain rancangan yang telah dibuat sebelumnya dikodekan dengan bahasa pemroraman tertentu untuk menjadi sebuah aplikasi. Pada tahap implementasi dilakukan coding berdasarkan dari perancangan dan analisa kebutuhan yang telah ditetapkan sebelumnya. Coding atau pengkodean merupakan penerjemahan desain dalam bahasa yang bisa dikenali oleh komputer (Rulyana \& Borman, 2014). Pada penelitian ini implementasi coding dengan menggunakan menggunakan bahasa pemrograman PHP (Hypertext Prepocessor), Framework Bootstrap, dan $M y S Q L$ sebagai basis datanya. Tampilan pertama kali sistem dibuka adalah halaman utama. Halaman ini disediakan hyperlink yang berfungsi untuk memudahkan pengguna (user) untuk memilih menu saat ingin menggunakan sistem ini. Pada halaman ini, user dapat memilih untuk login sesuai dengan levelnya. Hyperlink tersebut adalah berupa menu untuk menuju halaman login yang terdapat tiga buah, yaitu login kesiswaan, login pengurus, dan login anggota. Ketika user memilih salah satu dari menu tersebut, maka sistem akan menampilkan halaman login yang disesuaikan dengan level user yang mengakses. Berikut ini adalah tampilan dari halaman utama.

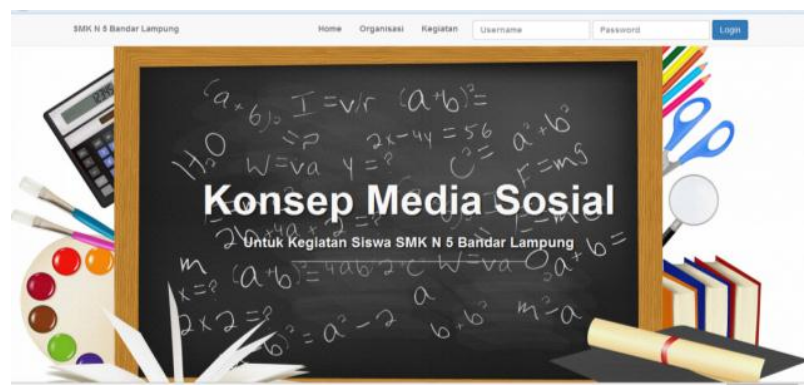

Gambar 3. Halaman Uama Sistem Informasi Kegiatan Kesiswaan Dengan Konsep Media Sosial

Setelah berhasil login halaman beriktnya adalah halaman dashboard kesiswaan yaitu halaman ketika user anggota organisasi dan kesiswaan telah berhasil login. Dashbord untuk level user kesiswaan disediakan fitur untuk mengelola data organisasi, mengelola kepengurusan organisasi, mengirim pesan dan melihat kiriman dari anggota organisasi. Sedangkan pada dashbord untuk anggota orgnaisasi disediakan fitur untuk melihat anggota sesama organisasi dan melihat kiriman dari pengurus, seperti pada gambar 4 berikut ini.

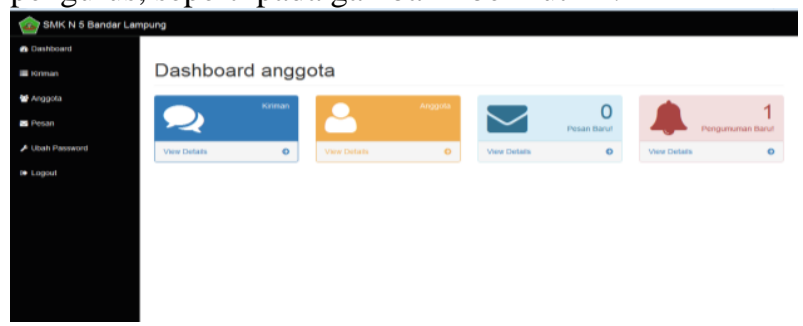

Gambar 4. Dashbord Anggota

Untuk dapat memberikan informasi dan saling bertukar informasi pengguna sosial media sistem informasi kegiatan kesiswaan ini dapat membuat kiriman pada form kiriman. Form kiriman digunakan untuk menulis kiriman oleh pengurus. Pada halaman ini terdapat isisan judul kiriman, tanggal kegiatan, isi kiriman, serta lampiran-lampirannya, seperti pada gambar 5 berikut ini.

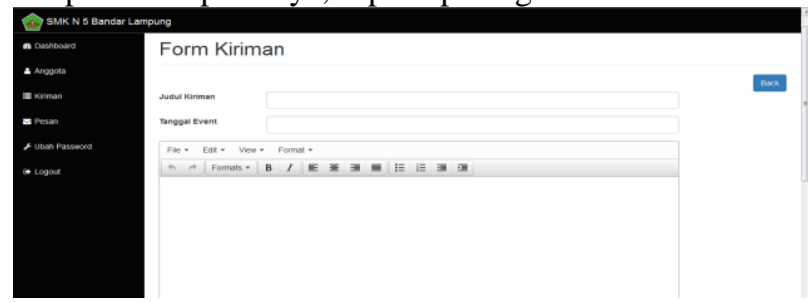

Gambar 5. Form Kiriman 
Untuk mengomentari kiriman yang telah dikirimkan oleh pengurus organisasi kesiswaan anggota dapat mengomentari kiriman tersebut melalui form tambah komentar yaitu sebuah form yang terdapat pada halaman detail kiriman yang digunakan untuk mengomentari sebuah kiriman. Pada sistem ini, user dapat berbalas komentar terhadap suatu kiriman. Berikut ini adalah tampilan dari tambah komentar

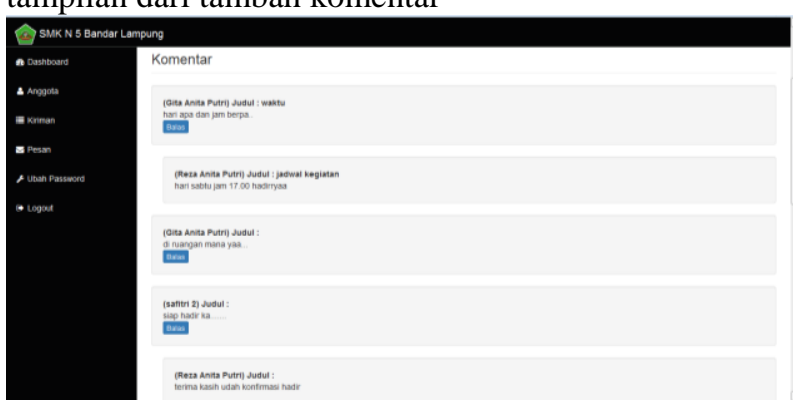

Gambar 6. Form Tambah Komentar

Untuk mengirim pesan pada sistem informasi kegiatan kesiswaan dengan konsep media sosial ini dapat melalui fitur kirim pesan. Pada fitur kirim pesan kesiswaan dapat mengirim pesan kepada siswa yang mengikuti kegiatan organisasi sehingga siswa dapat bertanya jawab secara pribadi tentang kegiatan organisasi. Kemudian siswa yang mendapatkan pesan dapat melihat kiriman pesan melaui inbox.

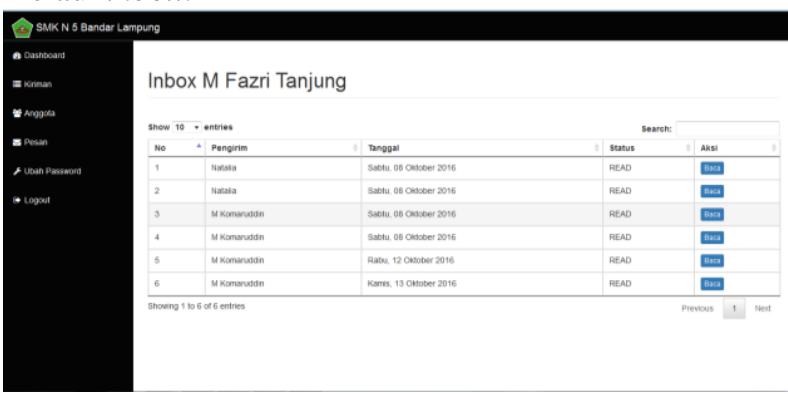

Gambar 7. Fitur Inbox Untuk Melihat Kiriman Pesan Pribadi

\subsection{Pengujian Sistem}

Agar pengguna dapat menggunakan sistem maka sistem yang telah dikembangkan sebelum digunakan oleh pengguna harus bebas dari beberapa kesalahan kesalahan. Oleh karena itu, sistem harus diuji terlebih dahulu agar dapat menemukan kesalahan - kesalahan. Pada penelitian ini sistem diuji respon time nya. Dalam pengujian response time ini akan dilakukan dengan menggunakan aplikasi Apache Jmeter yaitu aplikasi desktop yang berjalan diatas Java VM yang dapat mengukur kinerja sistem dan load-test dari aplikasi client/server. Berikut ini merupakan tampilan awal aplikasi Apache Jmeter: Berikut ini adalah hasil pengujian respone time dengan uji 50 user menggunakan aplikasi Apache Jmeter.

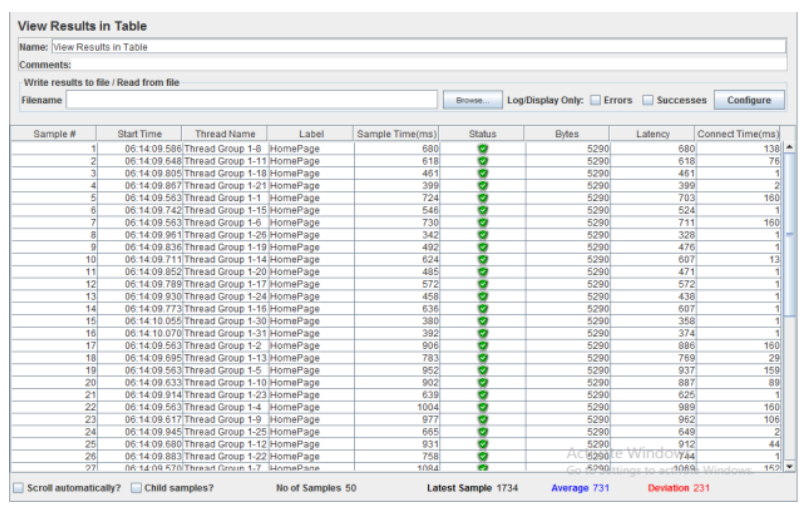

Gambar 7. Pengujian Respone Time Dengan 50 User

Berdasarkan hasil yang didapat, maka disimpulkan bahwa dalam pengukuran HTTP Request dengan jumlah sampel 50 user berhasil melakukan permintaan dalam 1 waktu, tidak ada yang gagal. Ketika melakukan request, rata-rata response time yang diperoleh yaitu 731 milidetik atau sekitar 0,7 detik diakses pada pukul 06:14 WIB.

\section{Kesimpulan}

Berdasarkan pembahasan yang telah diuraikan maka dapat disimpulkan :

1. Dengan membangun sistem media sosial, penyampaian informasi tentang kegiatan organisasi sekolah pada SMK XYZ dapat membantu organisasi kesiswaan dalam mengorganisir penyampaiaan informasi dengan cara melibatkan dari organisasi kesiswaan dalam memantau kegiatan siswa melalui sistem.

2. Sistem informasi kegiatan kesiswaan untuk organisasi siswa pada SMK XYZ telah enerapkan konsep media sosial karena pada sistem yang dikembangkan terdapat fitur-fitur yang harus media sosial yang terdiri dari fitus sociality, openess, contributors, contents, technology dan location.

3. Pada pengujian respontime dengan menggunakan Apache Jmeter, sistem mampu menangani dengan baik untuk akses 50 user secara bersamaan.

\section{Daftar Pustaka}

A. S., R., \& Salahudin, M. (2013). Modul Pembelajaran Rekayasa Perangkat Lunak ( Terstruktur dan Berorientasi Objek). Bandung: Informatika.

Abadi, T. W., Fandrian, S., \& Utara, D. A. (2013). Media Sosial dan Pengembangan Hubungan Interpersonal Remaja di Sidoarjo. KANAL , 2 (1), 95-106.

Kosasi, S., \& Kuway, S. M. (2012). Studi Analisis Persyaratan Kebutuhan Sistem Dalam Menghasilkan Perangkat Lunak Yang Berkualitas. Jurnal Ilmiah SISFOTENIKA, 2, No. 1.

Rulyana, D., \& Borman, R. I. (2014). Aplikasi Simulasi Tes Potensi Akademik Berbasis Mobile Platform Android. Seminar Nasional FMIPA-Universitas Terbuka. DKI Jakarta. 
Schlagwein, D., Schoder, D., \& Fischbach, K. (2011). Social Information Systems: Review, Framework, And Research Agenda. Thirty Second International Conference on Information Systems.

Simarmata, J. (2010). Rekayasa Perangkat Lunak. Yogyakarta: Andi Offset.

Sommervile, I. (2011). Software Engineering Ninth Edition. Addison-Wesley.

Watie, E. D. (2011). Komunikasi dan Media Sosial. THE MESSENGER , III (1), 69-75. 